\title{
The Effect of Different Bougies Sizes on Short Term Excess Body Weight Loss in Laparoscopic Sleeve Gastrectomy
}

\author{
Ghada Morshed MD MRCS; Salah Said Soliman MD MRCS.
}

Departments of Surgery, Fayoum University, Egypt.

Background: Laparoscopic sleeve gastrectomy has been considered recently as the best single bariatric surgery in morbidly obese subjects.

Patient and methods: This prospective study was conducted in Surgery Department, Fayoum University Hospital in the period between August 2013 and August 2014.The study included 20 cases of morbidly obese patients (with $B M I \geq 40 \mathrm{Kg} / \mathrm{m}^{2}$ or $\geq 35 \mathrm{Kg} / \mathrm{m}^{2}$ assosciated with other comorbidities) and this was via laparoscopic sleeve gastrectomy technique, we used different bougie sizes ranged from 32-46 F.

Results: There is a significant relation between the bougie size and the volume excised and the change in BMI detected after six months (large volumes excised were with small bougies sizes), and this correlation is statistically significant $P$ value $=0.005$.

Conclusion: We can conclude from this study that there is a significant relation between the bougie size and the short term EBWL.

Key words: Obesity, bariatric surgery, sleeve gastrectomy, bougie size.

\section{Introduction:}

The incidence of obese patients is rising, and $40 \%$ of American population will be affected with obesity by the year 2025 . $^{1}$

Recently there has been an interest in the surgical treatment of morbid obesity in increased incidence of obesity, and use of the laparoscopic bariatric surgery. Bariatric surgery proved success in providing loss of weight, correction of comorbidities and short-term and also long-term outcomes, decreasing overall mortality. ${ }^{2-4}$

The incidence of performing laparoscopic Roux-en-Y Gastric Bypass (LRYGBP) procedures have increased recently.

New bariatric procedures have been accepted by surgeons as happened in laparoscopic adjustable gastric banding (LAGB). ${ }^{5-6}$

Because of high rate of failure (in longterm) the literature indicates a few LAGB procedures but more Roux-en-Y gastric bypass (RYGBP) procedures and surgeons are preferring laparoscopic RYGBP. ${ }^{7-9}$

Laparoscopic Sleeve Gastrectomy (LSG) is being done more frequently and is very "trendy" among bariatric laparoscopic surgeons. ${ }^{10,11}$

Achieving considerable loss of weight, it has been considered by some bariatric surgeons to be used as a solely bariatric procedure.

\section{Aim of the study:}

In this prospective study the primary aim of work is to evaluate the effect of different bougies sizes and volume of the excised part of the stomach in laparoscopic sleeve gastrectomy on the short term excess weight loss of the patient candidate for this operation including all cases where LSG is indicated

\section{Patients and methods:}

This prospective study was conducted in Surgery Department, Fayoum University Hospital in the period between August 2013 and August 2014. The study included 20 cases of morbidly obese patients (with BMI $\geq 40 \mathrm{Kg} / \mathrm{m}^{2}$ or $\geq 35 \mathrm{Kg} / \mathrm{m}^{2}$ assosciated with other comorbidities) and this via laparoscopic 
sleeve gastrectomy technique, and all of them had failed in trials of conservative management including dietary control and they are bulky eater but non sweet eater also ASA I and II.

Different options for management of morbid obesity were discussed in details with the patients with emphasis on the benefits and more importantly the potential complications and side effects of the LSG.

Laboratory investigations in the form $\mathrm{CBC}, \mathrm{FBS}$, renal functions, liver functions, coagulation profile, lipid profile beside hormonal assay ; to detect any endocrinal causes of obesity as hypothyroidism. Pulmonary evaluation;including chest X-ray \& pulmonary function tests. Cardiac assessment; ECG \& Echocadiography if needed.

Patients were then operated on after following a two week low caloric (800־$1000 \mathrm{Kcal} / 24 \mathrm{hrs}$ ) preoperative diet. Informed consent was obtained from all patients.

We included patients who are psychologically stable with no endocrinal causes for obesity and accepting surgery,we excluded patients pregnant or breast feeding females,psychologically unstable patients and any patient suffers from significant longstanding heart/lung disease other severe systemic disease.

\section{Surgical procedure:}

A nasogastric tube was inserted at the begining to decompress the stomach. A window was dissected at the junction of the greater curvature and the greater omentum, around $10 \mathrm{~cm}$ from the pylorus. Division of the gastroepiploic, short gastric and posterior fundic vessels is done starting at $4 \mathrm{~cm}$ proximal to the pyloric ring all the way till the angle of His using the (ultracision Harmonic scalpel) (Harmonic; Ethicon Endosurgery, Cincinnati, OH, USA).

Once the dissection part is over, a bougie was introduced orally by the anaesthisiologist throught the oesophagus and inside the stomach, the bougie sizes used ranged from $32-46$ F. The surgeon then guides it along the lesser curvature and into the pyloric channel and duodenal bulb.

Gastric transection begins 4 to $6 \mathrm{~cm}$ proximal to the pylorus. A $60-\mathrm{mm}$, green or gold cartilage was placed across the antrum through the right midepigastric port and was fired. The second stapler was placed approximately 1 to $2 \mathrm{~cm}$ from the border of the lesser curvature in the direction of the gastroesophageal junction

Sequential firings of the stapler along the border of the bougie on the lesser curvature completes the gastric transection at the left crus. After completing the transection, the entire staple line is inspected carefully to make sure that the staples are well formed especially at the antrum where the stomach is thickest. A layer Vicryl 3/0 can be taken either continuous or interrupted simple at the junctions staples line.

Evaluation of the volume of the excised part of the stomach by:

1. Putting the excised part of the stomach on a table.

2. Adjusting the height of the normal saline bag to be 1 meter from the table.

3. An intravenous set was inserted into the bag and was inserted into the excised part of the stomach through a wide bore canula (14 G).

4. The saline was left to drip into the excised part of the stomach until complete distension was noticed.

5. Waiting for 3 minutes after stopping of dripping to assume filling the excised part of the stomach.

6.Measuring the volume of the saline filling the stomach part was done.

7.All data were statistically analysed.

Statistical analysis of data collected: Data collected were statistically analysed using Pearson's linear correlation test where $\mathrm{p}$ value $<0.05$ is statistically significant.

\section{Results:}

- $\mathrm{P}$ value $=0.153$ and it is statistically insignificant.

Although there is weak correlation between the volume excised and the EBWL detected after one month, this correlation is statistically insignificant. 
Correlation is significant at the 0.01 level (2-tailed).

- Correlation Coefficient: $\mathrm{R}=0.604$

- $\mathrm{P}$ value $=0.005$ and it is statistically significant.

There is moderate correlation between the volume excised and the change in BMI detected after six months, and this correlation is statistically significant $\mathrm{P}$ value $=0.005$.

\section{Discussion:}

The World Health Organization estimated that globally, in 2005, approximately 1.6-billion adults were overweight and at least 400 million were obese. The most recent data suggest that as a result of the sedentary life styles lead by most of the population and high carbohydrate load of the average meal, Egypt has become one of the countries badly affected by the obesity epidemic with an estimated just less than third of the adult population classified as obese with a much higher prevalence amongst females than males. Unfortunately, obesity and overweight can have a variety of adverse health consequences associated with a high rate of death, such as type 2 diabetes mellitus (T2DM), dyslipidemia, hypertension, obstructive sleep apnea (OSA), certain types of cancer, steatohepatitis, gastroesophageal reflux, arthritis, polycystic ovary syndrome (PCOS), and infertility. ${ }^{12}$

With all the proven benefits and the well documented safety of bariatric surgery, It was rather expected that there will be a massive interest in this specialty that was eventually translated into numbers with a massive increase in the number of bariatric procedures performed worldwide The most commonly performed bariatric procedures today are adjustable gastric banding (AGB), standard Roux-en-Y gastric bypass (RYGB), and sleeve gastrectomy (SG).

A recent worldwide survey reported that over $90 \%$ of world bariatric surgery was performed laparoscopically. More specifically, laparoscopic AGB (LAGB) was performed the most worldwide followed by the gastric bypass and then the relatively newer procedure the sleeve gastrectomy. ${ }^{13}$
The RYGB is the most common technique in United States. Biliopancreatic diversion (BPD) was performed in $0.9 \%$ worldwide, and the BPD with duodenal switch (BPDDS) was performed in $0.8 \% .{ }^{14}$

One of the contributing factors to these surgical procedures being less commonly performed is that they are technically more difficult than gastric bypass and are more prone to micronutrient and macronutrient deficiencies. BPD and BPD-DS might have a role in the treatment of extremely obese patients or in the treatment of patients who have failed to lose weight with the other bariatric procedures as they are effective procedures in weight loss and weight loss maintenance. ${ }^{15}$

In a series of 1120 patients that underwent LAGB in 2002, it was reported that the early peri-operative complication rate is $1.5 \%$ while the late complication rate is $14 \% .{ }^{16} \mathrm{Re}-$ operation and band failure are still the most challenging problems of this surgery. A metaanalysis study has shown that around $7.7 \%$ of patients require re-operation for band removal, usually due to intolerance, infection, band slippage, and band erosion. Moreover, the degree of weight reduction attained was relatively minimal compared to other bariatric procedures (sleeve gastrectomy and gastric bypass). The procedure is less effective for patients with poor dietary compliance and those with high BMIs. In contrast to patients with lower BMIs $(<60 \mathrm{~kg} / \mathrm{m} 2)$, super-obese patients require a longer period of follow-up to accomplish a similar percentage of EBW loss. ${ }^{17}$

RYGB is certainly one of the more technically challenging laparoscopic procedures performed today. Both the size of the obese patient and the complexity of these reconstructive procedures create the major technical barriers. Surgeons must perform such complex tasks as gastric pouch creation, Roux limb creation, two anastomoses, and closure of mesenteric defects (to avoid internal hernia formation). Advanced skills such as laparoscopic suturing, stapling, and dissection techniques must be mastered. Patient factors such as massive obesity (BMI $>60)$, severe 
hepatomegaly, prior abdominal surgery, and reoperative bariatric surgery may increase the degree of difficulty by several magnitudes. Early perioperative complications for RYGB include postoperative anastomotic leak, bowel obstruction, and hemorrhage. ${ }^{18}$ Late surgical complications for RYGB include anastomotic stricture, bowel obstruction, and incisional hernia. ${ }^{19}$

The weight loss associated with a sleeve gastrectomy alone can be substantial. In addition, several small series have noted a significant decrease in associated comorbidities after a sleeve gastrectomy. Several studies have been published that have suggested that a laparoscopic sleeve gastrectomy can be performed as a definitive weight loss procedure. ${ }^{20}$

Interesting data were presented at the First International Consensus Summit for Sleeve Gastrectomy in October 2007. According to this summit, there were 10 centers in the USA that had achieved a 5-year follow-up. Only one death was reported in the first 260 patients. Sleeve gastrectomy according to the data presented at the summit represents $2 \%$ of the bariatric operations in the USA. This took place despite the fact that the surgery had no specific insurance code. ${ }^{21}$ Compared to our study there were no mortalities.

Importantly, rates of complications have varied significantly between authors. ${ }^{22}$ With gastric leak being the complication of greatest concern. Anecdotally it would seem that when leaks occur in sleeve gastrectomy they are usually proximal and result in significant difficulties. Often multiple operations are required, with early intervention being the key to resolution. Prolonged fistulae are common. Collections are practically inevitable. Leaks appear more difficult to resolve than leaks from gastric bypass surgery, presumably because of the high gastric pressures and acid and bile content in the gastric sleeve remnant. Gastric stenting may have a role in leak management. In addition sleeve gastrectomy is an irreversible procedure. ${ }^{23}$ Compared to our study there were no leaks and the complications were lung atelectasis, fever and skin bruises and all were treated conservatively.

With the development of new multidetector computed tomographic (CT) techniques and software, radiologists can now play an important role in predicting the outcome of the restrictive bariatric procedures. Although other factors should always be taken in consideration, as the neurohormonal effect of LSG in reduction of ghrelin levels in the body, residual gastric volume remains the most important in all factors concerning restriction of stomach size, and has always been the main concern of surgeons in the bariatric surgery community.

We would like to shed a light on the technique through which the residual gastric volume has been assessed, CT volumetry, which has proven its efficacy in evaluation of the volume of other organs, such as the liver, but has not been widely used in assessing the stomach. More research is needed in order to prove its accuracy with this particular organ, which, if done, should provide a true evolution in the prediction of the outcome of the restrictive bariatric procedures, but in our study we measure the volume of excised part of the stomach in LSG operation to the weight loss within the first six months postoperative with some details about month by month EBWL beside a brief view about comorbidities related to obesity such as diabetes mellitus and hypertension .

In our prospective study, the number of cases done was 20 patients. All procedures were performed laparoscopically without conversions.

The age of the study population ranged between 19 and 53 years with a mean of 33.7 years.

The study comprises 8 males and 12 females.

The BMI of the study population range from 37.7 to 59.5 with a mean BMI of 48.6.

Comorbidities included diabetes mellitus in 8 cases (type II;non-insulin dependent diabetes mellitus) and overlapped with primary hypertension in 2 cases.

The BMI dropped $6 \mathrm{~m}$ postoperative to range from 28 to 42.2 with a mean BMI of 34.6 . 

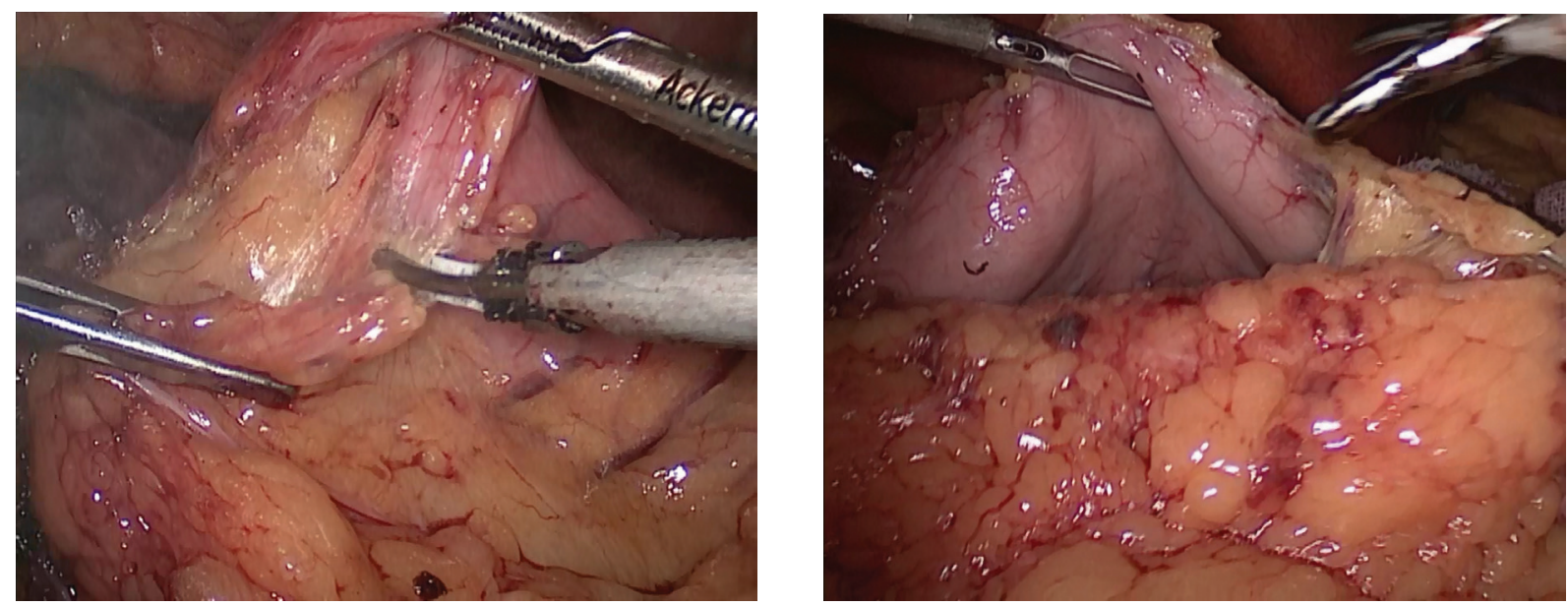

Figures (1,2): Showing division of the vascular supply of the greater curvature of the stomach.

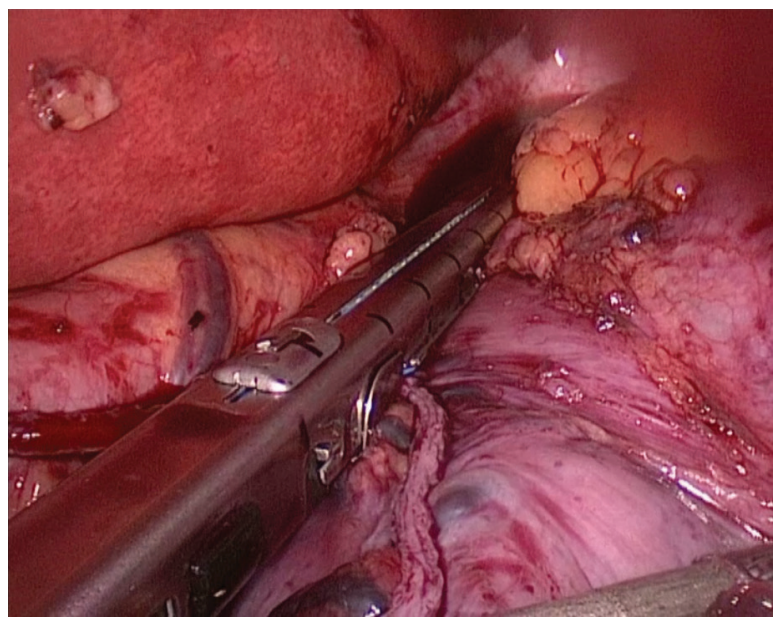

Figure (3): Gastrectomy by stapler $6 \mathrm{~cm}$ proximal to the pylorus.

\section{$1 \mathrm{M}$ Wt loss}

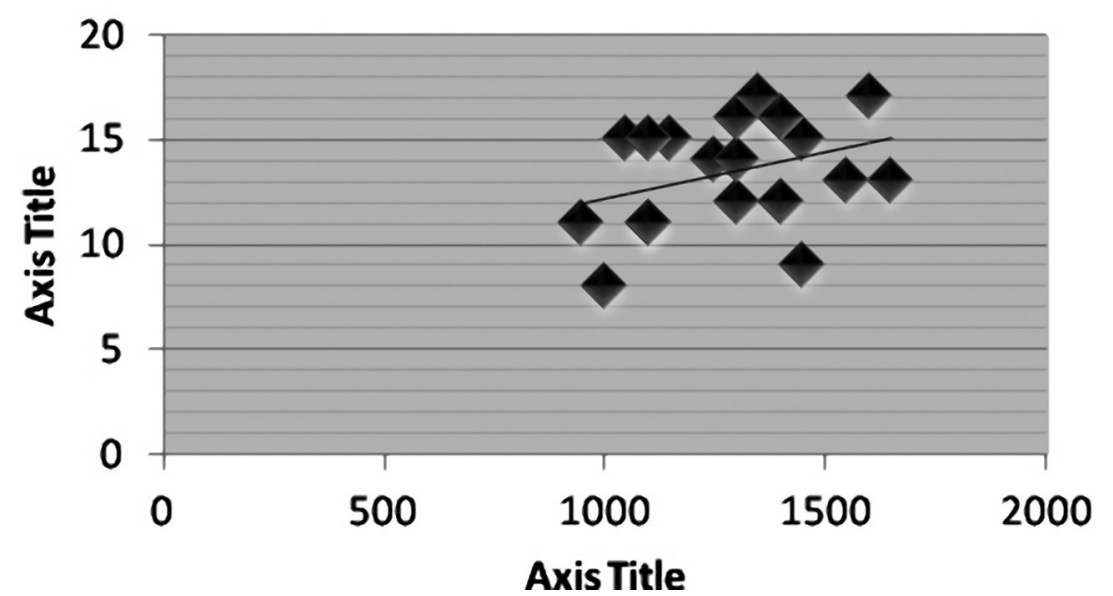

$1 \mathrm{MWt}$ loss

- Linear (1M Wt loss)

Figure (4): Studying correlation between Volume excised and weight loss one month after the operation

The excess body weight loss ranged from 8 to $17 \mathrm{Kgs}$. With mean of $13.5 \mathrm{Kgs}$. In the first month postoperative.

The excess body weight loss ranged from
3 to $10 \mathrm{Kgs}$. With mean of $5.75 \mathrm{Kgs}$. In the second month postoperative.

The excess body weight loss ranged from 3 to $9 \mathrm{Kgs}$. With mean of $5.4 \mathrm{Kgs}$. In the third 


\section{$6 \mathrm{~m}$ Wt loss}

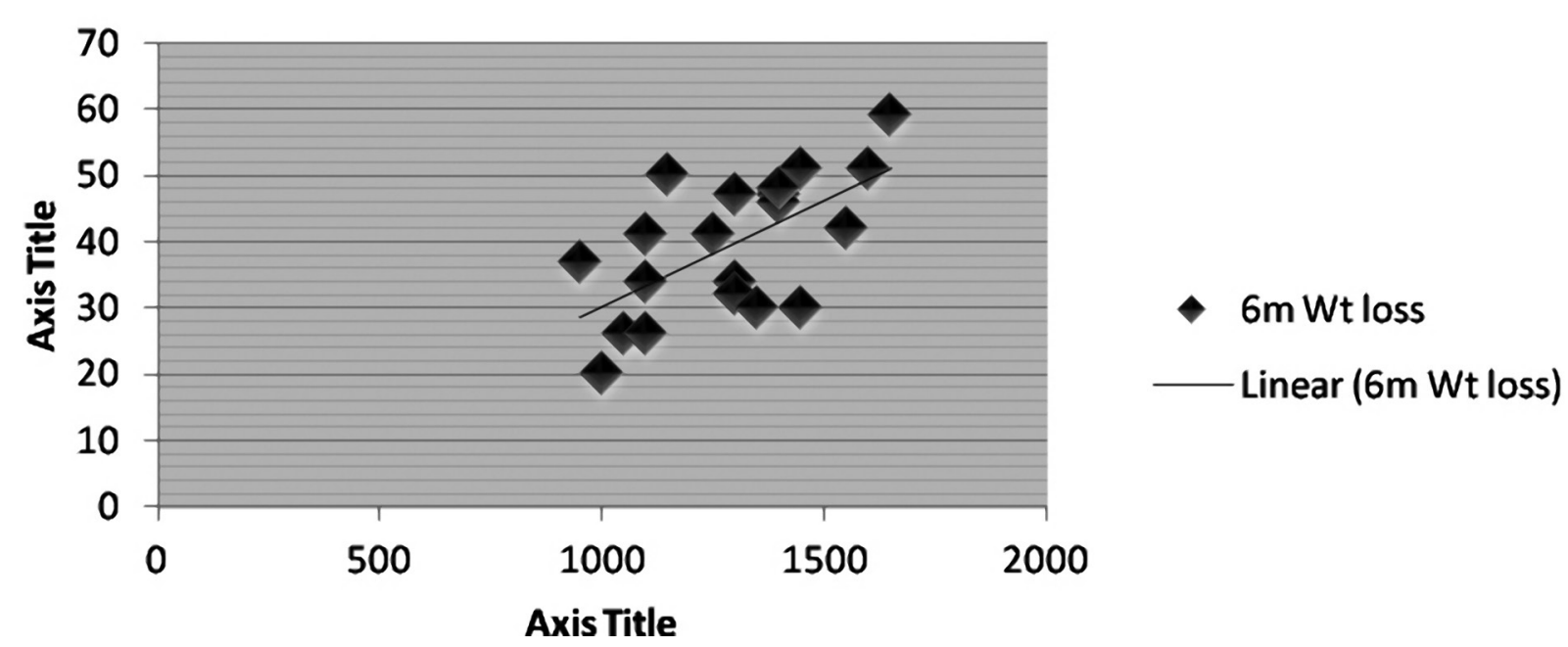

Figure (5): Studying correlation between Volume excised and weight loss six months after the operation.

\section{difference BMI}

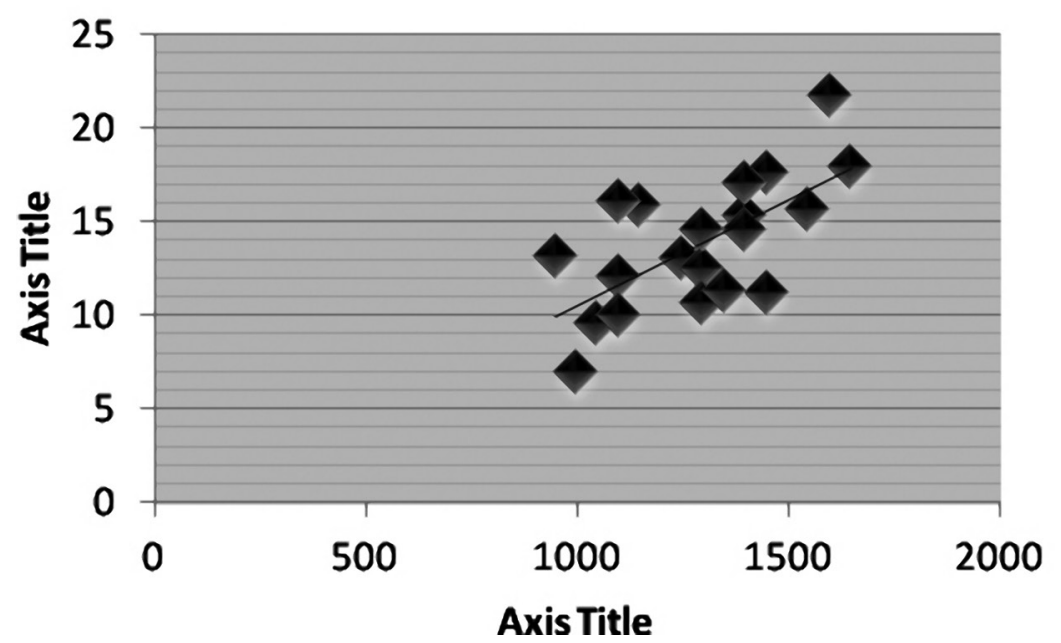

- difference BMI Linear (difference BMI)

Figure (6): Studying correlation between Volume excised and change in BMI six months after the operation.

month postoperative.

The excess body weight loss ranged from 2 to $10 \mathrm{Kgs}$. With mean of $4.95 \mathrm{Kgs}$. In the fourth month postoperative.

The excess body weight loss ranged from 0 to $12 \mathrm{Kgs}$. With mean of $4.85 \mathrm{Kgs}$. In the fifth month postoperative.

The excess body weight loss ranged from 0 to $10 \mathrm{Kgs}$. With mean of $5.35 \mathrm{Kgs}$. In the sixth month postoperative.

The excess body weight loss within the first 6 months postoperative ranged from 20 to $59 \mathrm{Kgs}$. With mean of $39.6 \mathrm{Kgs}$. The percentage of the excess body weight loss ranged from $36 \%$ to $80 \%$ with a mean of $60.1 \%$. In the first 6 months post-operative. Compared to another study that showed excess body weight loss ranged from 117.7 $\pm 17.1 \mathrm{KG}$ to $91.2 \pm 17.2 \mathrm{KG}$. The BMI dropped from $42.7 \pm 4.7 \mathrm{Kg} / \mathrm{m} 2$ to $33.0 \pm 4.9$ $\mathrm{Kg} / \mathrm{m} 2$, the mean excess body weight loss was $49.0 \%$ after 6 months. ${ }^{24}$

The volume of the excised part of the stomach range from $950 \mathrm{ml}$. (with bougie $46 \mathrm{~F}$ ) to $1650 \mathrm{ml}$. (with bougie $32 \mathrm{~F}$ ) with mean of $1292.5 \mathrm{ml}$.

Small size bougies (32F-36F) were associated with large volumes excised and 
Table (1): Descriptive statistics

\begin{tabular}{|l|l|l|l|l|l|l|}
\hline Descriptive Statistics & Number & Range & Minimum & Maximum & Mean & Std. Deviation \\
\hline & 20 & 34.00 & 19.00 & 53.00 & 33.55 & 7.68782 \\
\hline Age & 20 & 22.30 & 37.20 & 59.50 & 48.42 & 6.25902 \\
\hline Preoperative BMI & 20 & 700.00 & $\begin{array}{l}950.00 \\
\text { Bougie46F }\end{array}$ & $\begin{array}{l}1650.00 \\
\text { Bougie32F }\end{array}$ & 1292.50 & 201.49115 \\
\hline Volume excised & 20 & 9.00 & 8.00 & 17.00 & 13.5 & 2.58538 \\
\hline One Month WT loss & 20 & 39.00 & 20.00 & 59.00 & 39.6 & 10.36390 \\
\hline Six Month WT loss & 20 & 14.80 & 6.90 & 21.70 & 13.8 & 3.47214 \\
\hline Change in BMI after 6m & 20 & & & & & \\
\hline Valid N (listwise) & & & & & & \\
\hline
\end{tabular}

more weight loss than large size bougies (40F-46F).

In our study by studying correlation between Volume excised and weight loss one month after the operation showed that there is weak correlation between the volume excised and the weight loss detected after one month ,however this correlation is statistically insignificant $(\mathrm{P}$ value $=0.153)$.

Studying correlation between volume excised and weight loss six months after the operation showed that there is moderate correlation between the volume excised and the weight loss detected after six months, and this correlation is statistically significant ( $\mathrm{P}$ value $=0.004)$.

Studying correlation between volume excised and change in BMI six months after the operation showed that there is moderate correlation between the volume excised and the change in BMI detected after six months, and this correlation is statistically significant $(\mathrm{P}$ value $=0.005)$

We can conclude from this study that there is a significant relation between the volume of the excised part of the stomach( according to bougie size) and the short term EBWL although insignificant in the first month EBWL but the total EBWL in the first 6 months post-operative indicate a significant relation.

Although we believe that this study can be of great benefit for the assessment of the post-operative follow up for the laparoscopic sleeve gastrectomy, yet more patients and longer period of follow up are needed to better judge this operation.

\section{Reference:}

1- Buchwald H, Avidor Y, Braunwald E, Jensen MD, Pories W, Fahrbach K, Schoelles K: Bariatric surgery: A systematic review and meta-analysis. JAMA 2004; 292: 1724-1737.

2- Maggard MA, Shugarman LR, Suttorp M, Maglione M, Sugerrnsn HJ, Livingston EH, Nguyen NT, Li Z, Mojica WA, Hilton L, et al: Meta-analysis: Surgical treatment of obesity. Ann Intern Med 2005; 142: 547-559.

3- Sugerman HJ, Krai JG: Evidence-based medicine reports on obesity surgery a critique. Int J Obes (Lond) 2005; 29: 735-745.

4- Christou NV, Sampalis JS, Liberman M, Look D, Auger S, McLean AP, MacLean LD: Surgery decreases long-term mortality, morbidity, and health care use in morbidly obese patients. Ann Surg 2004; 240: 416423; discussion 423-424.

5- Flum DR, Dellinger EP: Impact of gaslnc bypass operation on survival, a populationbased analysis. J Am Coll Surg 2004; 199: 543-551.

6- Muller MK, Attigah N, Wildi S, Hahnloser D Hauser R, Glavien PA, Weber M: High secondary failure rate of rebanding after failed gastric banding. Surg Endosc 2008; 22: 448-453 .

7- Weber M, Muller MK, Bucher T, Wildi S, Dindo D, Horber F, Hauser R, Clavien PA: Laparoscopic gastric bypass is superior to laparoscopic gastric banding for treatment of morbid obesity. Ann Surg 2004; 240: 
975-982, discussion 982-983.

8- Weber M, Muller MK, Michel JM, Belal R, Horber F, Hausei R, Clavien PA: Laparoscopic Roux-en-Y gastric bypass, but not rebanding, should be proposed as rescue procedure for patients with failed laparoscopic gastric banding. Ann Surg 2003; 238: 827-833, discussion 833-834.

9- Hess DS, Hess DW: Biliopancreahc diversion with a duodenal switch. Obes Surg 1993; 8: 267-282.

10- Hess DS, Hess DW, Oakley RS: The biliopancreatic diversion with the duodenal switch: Results beyond 10 years. Obes Surg 2005; 15: 408-416.

11- Silecchia G, Boru C, Pecchia A, Rizzello M. Casella G, Leonetti F, Basso N: Effectiveness of iaparoscopic sleeve gastrectomy (first Stage of biliopancreatic diversion with duodena! switch] on co-morbidities in superobese high-risk patients Obes Surg 2006; 16: 1138-1144.

12- Guh DP, Zhang W, Bansback N, et al: The incidence of co-morbidities related to obesity and overweight: A systematic review and meta-analysis. BMC Public Health 2009; 9: 88.

13- Stevens J, Couper D, Pankow J, et al: Sensitivity and specificity of anthropometrics for the prediction of diabetes in a biracial cohort. Obes Res 2001; 9: 696-705.

14- Buchwald H, Oien DM: Metabolic/bariatric surgery worldwide 2008. Obes Surg 2009; 19(12): 1605-1611.

15- Smith BR, Schauer P, Nguyen NT: Surgical approaches to the treatment of obesity: Bariatric surgery. Endocrinol Metab Clin North Am 2008; 37(4): 943-964.

16- O'Brien PE, Dixon JB, Laurie C, Anderson $\mathrm{M}$ : A prospective randomized trial of placement of the laparoscopic adjustable gastric band: Comparison of the perigastric and pars flaccida pathways. Obes Surg 2005; 15: 820-826.

17- Maggard MA, Shugarman LR, Suttorp M, Maglione M, Sugerman HJ, Livingston EH, Nguyen NT, Li Z, Mojica WA, Hilton L, Rhodes S, Morton SC, Shekelle PG: Metaanalysis surgical treatment of obesity. Ann Intern Med 2005; 142: 547-559.

18- Bult MJ, van Dalen T, Muller AF: Surgical treatment of obesity. Eur J Endocrinol 2008; 158(2): 135-145.

19- Papamargaritis DK, Pournaras DJ, Le Roux CW: Techniques, assessment, and effectiveness of bariatric surgery in combating obesity. Open Access Surgery 2010; 3: 123-136.

20- Frezza EE: Laparoscopic vertical sleeve gastrectomy for morbid obesity. The future procedure of choice? Surg Today 2007; 37: 275-281.

21- Akkary E, Duffy A, Bell R: Deciphering the Sleeve: Technique, Indications, Efficacy, and Safety of Sleeve Gastrectomy. Obes surg 2008; 18: 1323-1329.

22- Frezza EE, Reddy S, Gee LL, Wachtel MS: Complications after sleeve gastrectomy for morbid obesity. Obes Surg 2009; 19: 684-647.

23- Serra C, Baltasar A, Andreo L, Perez N, Bou $\mathrm{R}$, Bengochea $\mathrm{M}$, et al: Treatment of gastric leaks with coated self-expanding stents after sleeve gastrectomy. Obes Surg 2007; 17: 866-872.

24- Marek Buzga, Pavol Holeczy, Zdenek Svagera, Pavol Svorc Jr, VLadislava Zavadilova: Videosurgery. Mini Inv 2013; 8 (1): 22-28 